CLINICAL STUDY

\title{
Patients with primary hyperparathyroidism have lower circulating sclerostin levels than euparathyroid controls
}

\author{
A H van Lierop, J E Witteveen, N A T Hamdy and S E Papapoulos \\ Department of Endocrinology and Metabolic Diseases, Leiden University Medical Center, Albinusdreef 2, 2333 ZA Leiden, The Netherlands \\ (Correspondence should be addressed to S E Papapoulos; Email: m.v.iken@lumc.nl)
}

\begin{abstract}
Objective: In vitro and in vivo studies in animal models have shown that parathyroid hormone (PTH) inhibits the expression of the SOST gene, which encodes sclerostin, an osteocyte-derived negative regulator of bone formation. We tested the hypothesis that chronic PTH excess decreases circulating sclerostin in humans.

Design: We studied 25 patients with elevated serum PTH concentrations due to primary hyperparathyroidism (PHPT) and 49 patients cured from PHPT after successful parathyroidectomy (PTx; euparathyroid controls (EuPTH)).

Methods: We measured plasma PTH and serum sclerostin levels and the serum markers of bone turnover alkaline phosphatase, P1NP, and $\beta$-CTX.

Results: As expected by the design of the study, mean plasma PTH was significantly higher $(P<0.001)$ in PHPT patients (15.3 pmol/l; 95\% confidence interval (CI): 11.1-19.5) compared with that of EuPTH controls (4.1 pmol/l; 95\% CI: 3.6-4.5). PHPT patients had significantly lower serum sclerostin values compared with those in EuPTH subjects (30.5 pg/ml; 95\% CI: 26.0-35.1 vs $45.4 \mathrm{pg} / \mathrm{ml} ; 95 \%$ CI: 40.5-50.2; $P<0.001)$ and healthy controls $(40.0 \mathrm{pg} / \mathrm{ml} ; 95 \% \mathrm{CI}: 37.1-42.9 ; P=0.01)$. Plasma PTH concentrations were negatively correlated with serum sclerostin values $(r=-0.44 ; P<0.001)$. Bone turnover markers were significantly correlated with PTH, but not with sclerostin.

Conclusion: Patients with PHPT have significantly lower serum sclerostin values compared with PTx controls with normal PTH concentrations. The negative correlation between PTH and sclerostin suggests that SOST is downregulated by PTH in humans.
\end{abstract}

European Journal of Endocrinology 163 833-837

\section{Introduction}

Parathyroid hormone (PTH) exerts its calciotropic action by acting directly on bone and kidney and indirectly on the intestine to increase the transport of calcium to the circulation. The skeletal effect of PTH is to increase the rate of remodeling (1), and it is generally believed that this effect is achieved by the binding of PTH to its specific receptor (PTHR1) on stromal/osteoblastic cells of the bone marrow. This in turn stimulates the production of RANK ligand and decreases that of its decoy receptor osteoprotegerin (2-5). However, recent in vitro and animal studies suggest that some of the effects of PTH on bone are also exerted by specific binding of the hormone to PTHR1 in osteocytes, resulting in inhibition of the expression of the SOST gene (6-9). This gene encodes sclerostin, a protein exclusively expressed in osteocytes in the skeleton (10), which decreases bone formation by binding to LRP $5 / 6$, resulting in inhibition of the Wnt signaling pathway in osteoblasts $(11,12)$.

Whether chronic PTH excess has similar effects on sclerostin secretion in humans as in animal models has not so far been investigated. In this study, we tested the hypothesis that chronic hypersecretion of PTH, as seen in patients with hyperparathyroidism, may decrease sclerostin secretion, and that PTH may thus represent a potential regulator of sclerostin production in humans. To this effect, we measured sclerostin in serum of patients with untreated primary hyperparathyroidism (PHPT) and in a control group of patients with PHPT after establishment of cure following parathyroidectomy (PTx).

\section{Subjects and methods}

\section{Patients}

Thirty-four consecutive patients with PHPT that was untreated, persistent, or recurrent following PTx, and 54 patients cured after successful PTx (euparathyroid controls, EuPTH) were studied. Inclusion criteria included willingness to participate in the study, no impairment in renal function (serum creatinine levels $<120 \mu \mathrm{mol} / \mathrm{l})$, adequate vitamin D status (25-hydroxy 
vitamin D (25-OHD) levels > $50 \mathrm{nmol} / \mathrm{l})$, and no use of bone and mineral metabolism modifying agents such as bisphosphonates, calcimimetics, or glucocorticoids.

We defined PHPT as plasma PTH concentrations above the upper limit of the normal laboratory reference range $(>8 \mathrm{pmol} / \mathrm{l})$ in the presence of increased serum calcium concentrations $(>2.55 \mathrm{mmol} / \mathrm{l})$.

Patients with EuPTH were included when cure was confirmed by postoperative normalization of serum PTH and calcium concentrations, which was sustained for at least 6 months after PTx.

As per inclusion criteria, nine patients were excluded from the PHPT group, three because of impaired renal function and six because of the use of bisphosphonates, and six were excluded from the EuPTH group because of the use of bisphosphonates.

The study was approved by the Medical Ethics Committee of the Leiden University Medical Center, and informed consent was obtained from all patients.

\section{Methods}

Serum biochemistry Serum calcium was adjusted for albumin binding; phosphate and creatinine were measured by semi-automated techniques. Serum alkaline phosphatase (ALP) activity was measured using a fully automated P800 modulator system (Roche BV). P1NP (a marker of bone formation) and $\beta$-CTX (a marker of bone resorption) were determined using the E-170 system (Roche BV). Plasma PTH was measured using the Immulite 2500 (Siemens Diagnostics, Breda, The Netherlands) and serum 25-OHD was measured using the LIAISON 25-OHD TOTAL assay (DiaSorin S.A./N.V., Bruxelles, Belgium).

Sclerostin measurement Sclerostin was measured in serum by an electrochemiluminescence assay (MSD 96-well MULTI-ARRAY Human Sclerostin Assay, Gaithersburg, MD, USA) in which two polyclonal antibodies were raised against the whole sclerostin molecule. The sclerostin standard for the assay was produced in an NSO-derived myeloma cell line, and the purity was checked by SDS-PAGE gel with silver stain. In our hands, the intra- and inter-assay coefficient of variation values were 4.9 and $7 \%$ respectively, the detection limit was $\pm 1 \mathrm{pg} / \mathrm{ml}$, and the detection range was $1-10000 \mathrm{pg} / \mathrm{ml}$.

Sclerostin was measured in the serum of 77 healthy subjects (30 males and 47 females, aged 20-77 years). All had normal serum calcium concentration, renal function, and bone turnover and none were using bisphosphonates, the calcimimetic cinacalcet, or glucocorticoids. Sclerostin was detected in the serum of all healthy subjects: mean $40.0 \mathrm{pg} / \mathrm{ml}(95 \%$ $\mathrm{CI}=37.1-42.9 \mathrm{pg} / \mathrm{ml}$ ), range $12.4-68.19 \mathrm{pg} / \mathrm{ml}$, while it was undetectable in the serum of three patients with sclerosteosis.

\section{Statistical analysis}

Data were analyzed using SPSS 16.0 (SPSS Inc., Chicago, IL, USA). Between-group differences in baseline characteristics and serum biochemistry were assessed by Student's $t$-test. Pearson correlation coefficients were calculated to assess correlations between PTH (after logarithmic transformation), sclerostin, and biochemical markers of bone turnover. A probability level of random difference of 0.05 was considered significant.

\section{Results}

\section{Baseline characteristics}

There were no differences in age, gender, weight, or body mass index between patients with PHPT and EuPTH controls (Table 1).

As expected by the inclusion criteria, mean serum calcium and PTH concentrations were significantly higher and those of phosphate significantly lower in the PHPT group compared with the EuPTH group in which PTH concentrations were detectable in all patients. There were no differences in serum 25-OHD or creatinine concentrations between the two groups.

Patients with PHPT had significantly higher levels of biochemical markers of bone formation (P1NP) and bone resorption $(\beta-\mathrm{CTX})$ compared with EuPTH controls. Combining all patients, there was a significant positive correlation between plasma PTH concentrations and the concentrations of all three measured biochemical markers of bone turnover (ALP: $r=0.23$, $P=0.047$; P1NP: $r=0.45, P<0.001$; $\beta$-CTX: $r=0.54$, $P<0.001)$. There was also a significant correlation between PTH and P1NP $(r=0.51, P=0.009)$ in the PHPT group, but not between PTH and ALP $(r=0.35$, $P=0.085)$, or PTH and $\beta$-CTX $(r=0.31, P=0.13)$. In the EuPTH group alone, PTH was not correlated with any of the biochemical markers of bone turnover (Table 2).

\section{Serum sclerostin}

Mean serum sclerostin level of patients with PHPT (30.5 pg/ml, 95\% CI: 26.0-35.1) was significantly lower than that of patients with EuPTH and healthy controls $(45.4 \mathrm{pg} / \mathrm{ml}, 95 \%$ CI: 40.5-50.2; $P<0.001$,

Table 1 Subject characteristics. Values are given as mean \pm s.D.

\begin{tabular}{llll}
\hline & PHPT & EuPTH & $\boldsymbol{P}$ value $^{\mathrm{a}}$ \\
\hline Male:female & $10: 15$ & $13: 36$ & 0.41 \\
Age (years) & $59.6 \pm 16.7$ & $62.4 \pm 10.9$ & 0.44 \\
Weight $(\mathrm{kg})$ & $80.0 \pm 18.2$ & $81.1 \pm 15.3$ & 0.78 \\
BMI $\left(\mathrm{kg} / \mathrm{m}^{2}\right)$ & $27.0 \pm 6.0$ & $28.1 \pm 4.6$ & 0.42
\end{tabular}

aPHPT versus EuPTH. 
Table 2 Biochemical measurements. Values are given as mean \pm s.D.

\begin{tabular}{lcccc}
\hline & PHPT & EuPTH & Reference range & $\boldsymbol{P}_{\text {value }}{ }^{\mathrm{a}}$ \\
\hline Calcium homeostasis & & & & \\
PTH (pmol/l) & $15.3 \pm 10.7$ & $4.1 \pm 1.6$ & $1.5-8.0$ & $<0.001$ \\
Calcium (mmol/l) & $2.61 \pm 0.13$ & $2.26 \pm 0.12$ & $2.15-2.55$ & $<0.001$ \\
Phosphate (mmol/l) & $0.92 \pm 0.14$ & $1.14 \pm 0.24$ & $0.90-1.50$ & $<0.001$ \\
25-OHD (nmol/l) & $53.1 \pm 34.3$ & $53.9 \pm 20.2$ & $30-120$ & 0.90 \\
Creatinine ( $\mu \mathrm{mol} / \mathrm{l})$ & $80.2 \pm 18.1$ & $76.8 \pm 14.7$ & $44-80$ & 0.39 \\
Bone turnover & & & & \\
ALP $(\mathrm{U} / \mathrm{l})$ & $87.0 \pm 23.0$ & $75.7 \pm 23.6$ & $40-20$ & 0.055 \\
P1NP $(\mathrm{ng} / \mathrm{ml})$ & $45.9 \pm 16.9$ & $34.0 \pm 15.5$ & $16-80$ & 0.004 \\
$\beta$-CTX $(\mathrm{ng} / \mathrm{ml})$ & $0.32 \pm 0.15$ & $0.17 \pm 0.11$ & $0.01-0.66$ & $<0.001$ \\
\hline
\end{tabular}

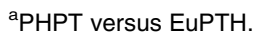

and $40.0 \mathrm{pg} / \mathrm{ml}, 95 \% \mathrm{CI}: 37.1-42.9 ; P=0.01$ respectively; Fig. 1). There was no significant difference in mean sclerostin values between EuPTH and healthy subjects $(P=0.13)$.

There was no significant correlation between PTH and sclerostin concentrations within each individual group of patients but there was a significant negative correlation between sclerostin and PTH when all patients were pooled together $(r=-0.44, P<0.001$; Fig. 2$)$.

There was no significant relationship between serum sclerostin and biochemical markers of bone turnover in patients with PHPT or in all patients combined.

\section{Discussion}

Data from our study demonstrates that in humans, chronic PTH excess, as observed in patients with PHPT, is associated with a significant decrease in circulating sclerostin and that there is a significant negative correlation between PTH and serum sclerostin levels. Taken together, these results suggest that, similar to animal models (6-9), PTH has a regulatory role in sclerostin production in humans also.

Sclerostin, a glycoprotein expressed by osteocytes in bone and encoded by the SOST gene, has emerged in recent years as an important regulator of bone formation in humans as well as in animals $(13,14)$. Inactivating mutations of the SOST gene leading to sclerostin deficiency have been shown to be associated with the rare skeletal disorder sclerosteosis, which is characterized by a marked increase in bone mass (13). Deletion of the Sost gene in mice has also been shown to increase bone formation, bone mass, and bone strength (14) demonstrating an evolutionary conservation of the function of sclerostin in the regulation of bone formation. Moreover, inhibition of sclerostin secretion by an MAB to sclerostin has been shown to increase bone formation and bone mass in rodents, primates, and humans (14-16). Conversely, transgenic mice overexpressing Sost have low bone mass and impaired biomechanical competence (17). The mechanism of action of sclerostin to decrease bone formation involves inhibition of the Wnt signaling pathway $(11,12)$, although its precise molecular mechanism and factors controlling its secretion are yet to be determined. Recent animal studies have shown that mechanical loading and high PTH levels downregulate the expression of Sost in osteocytes and decrease the production of sclerostin resulting in stimulation of bone formation $(8,18)$.

Human studies of sclerostin regulation have lagged behind due to lack of noninvasive techniques to determine sclerostin production. A number of assays have been recently developed for the measurement of sclerostin in blood. In our study, we used a sclerostin assay that proved to have excellent performance characteristics in our hands with a wide detection range. Sclerostin was detectable in serum in all healthy subjects studied, suggesting that the protein is secreted

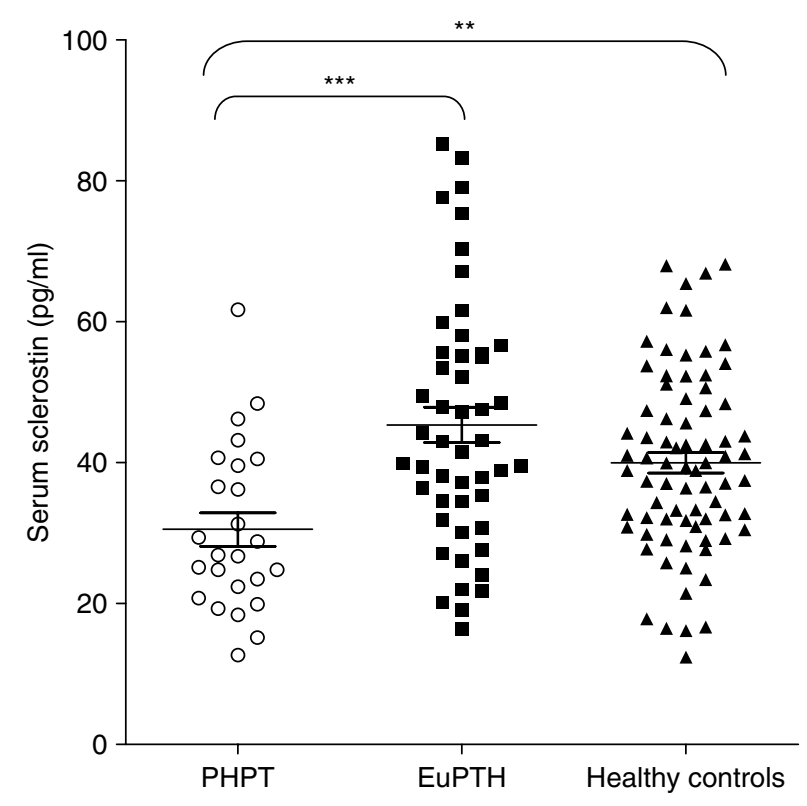

Figure 1 Serum sclerostin levels in PHPT, EuPTH, and healthy subjects. ${ }^{* \star} P<0.001,{ }^{* \star} P=0.01$ (Student's $t$-test). 


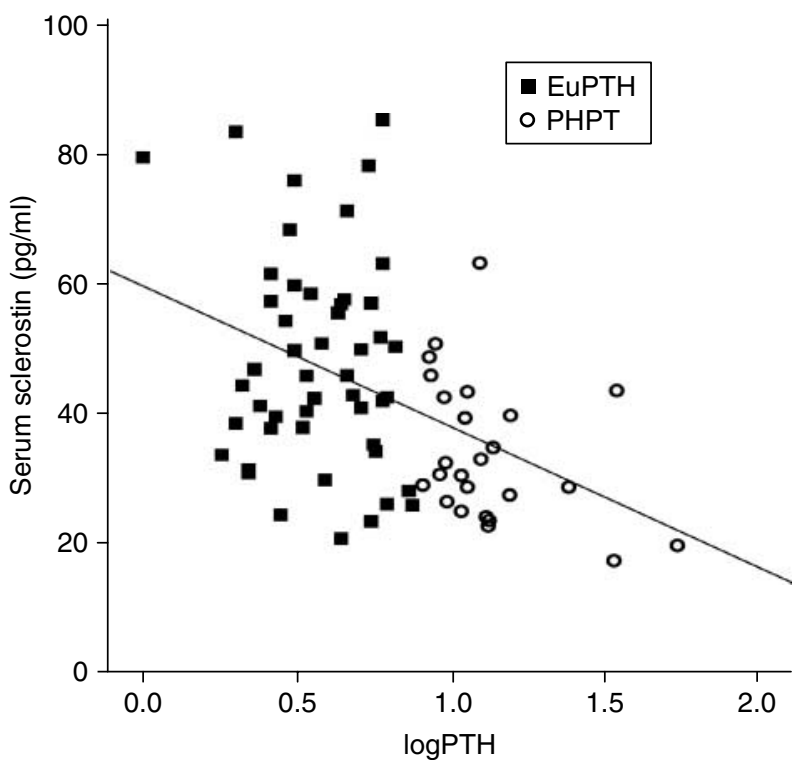

Figure 2 Relationship between circulating sclerostin and PTH levels. $r=-0.44, P<0.001$ (Pearson's correlation). PTH levels were log transformed because of skewness.

and enters the circulation, while it was undetectable in three patients with sclerosteosis in whom it was measured. The difference in absolute values with other commercial assays is not clear and may be related to different methodologies. We chose to study patients with PHPT in order to mimic as closely as possible the effect of chronic PTH excess on sclerostin, as previously studied in animals $(6,8)$. In addition, we chose to use as controls, patients with PHPT cured after PTx to exclude potential confounding factors, other than PTH excess.

We show here that serum sclerostin levels are significantly decreased in patients with chronic PTH excess due to PHPT compared with EuPTH and healthy subjects although there was an overlap of values between the groups. PTH has been shown to decrease SOST transcription in vitro $(6,7)$, and continuous and intermittent chronic administration of PTH to rodents is associated with decreased Sost mRNA and sclerostin expression in osteocytes $(6,7,9)$. Moreover, transgenic mice expressing a constitutively active PTH receptor in osteocytes exhibit decreased expression of sclerostin and increased Wnt signaling associated with increased bone mass (8). Additional evidence for an interaction between PTH and Sost/sclerostin was recently provided by a study showing that the anabolic actions of PTH on bone was blunted in Sost-overexpressing mice (19). In keeping with the notion of a regulatory role of PTH for sclerostin production, our data show a significant correlation between circulating PTH and sclerostin. These data extend those of Mirza et al. (20), who recently reported a negative relationship between serum PTH and sclerostin in healthy postmenopausal women, and those of Drake et al. (21), who showed that intermittent PTH treatment decreased serum sclerostin levels in postmenopausal women. Put together, these data suggest that SOST regulation by PTH is also conserved between humans and rodents.

As expected in the presence of chronic PTH excess, patients with PHPT had increased bone turnover as indicated by increased biochemical parameters of bone formation and resorption. There was a significant relationship between circulating PTH concentrations and serum P1NP and $\beta$-CTX. However, we did not find a significant relationship between biochemical parameters of bone turnover and serum sclerostin, either in patients with PHPT or the combined group of PHPT and EuPTH subjects. This lack of correlation between sclerostin and bone turnover markers was previously reported in healthy postmenopausal women (20) but not in elderly women (22). The functional significance of circulating sclerostin is as yet to be established.

The actions of PTH on bone are complex and involve a variety of signaling pathways in bone marrow stroma cells, osteoblasts, and osteocytes $(23,24)$. Despite the significant progress in our understanding of the actions of PTH on bone, it should be appreciated that the cellular and molecular actions of PTH, which determine the action of the hormone on bone remodeling and bone balance, have only been partially unraveled and studies are needed to further elucidate these actions.

\section{Declaration of interest}

The authors declare that there is no conflict of interest that could be perceived as prejudicing the impartiality of the research reported.

\section{Funding}

This work was supported by and carried out within the FP7 program Talos, funded by the EC (Grant no. TALOS:Health-F2-2008-201099).

\section{Acknowledgements}

We thank Dr N Biermasz for her help in obtaining blood samples from healthy volunteers.

\section{References}

1 Mosekilde L. Primary hyperparathyroidism and the skeleton. Clinical Endocrinology 200869 1-19. (doi:10.1111/j.13652265.2007.03162.x)

2 Huang JC, Sakata T, Pfleger LL, Bencsik M, Halloran BP, Bikle DD \& Nissenson RA. PTH differentially regulates expression of RANKL and OPG. Journal of Bone and Mineral Research 200419 235-244. (doi:10.1359/JBMR.0301226)

3 Lee SK \& Lorenzo JA. Parathyroid hormone stimulates TRANCE and inhibits osteoprotegerin messenger ribonucleic acid expression in murine bone marrow cultures: correlation with osteoclast-like cell formation. Endocrinology 1999140 3552-3561. (doi:10. 1210/en.140.8.3552) 
4 Locklin RM, Khosla S, Turner RT \& Riggs BL. Mediators of the biphasic responses of bone to intermittent and continuously administered parathyroid hormone. Journal of Cellular Biochemistry 200389 180-190. (doi:10.1002/jcb.10490)

5 Ma YL, Cain RL, Halladay DL, Yang X, Zeng Q, Miles RR, Chandrasekhar S, Martin TJ \& Onyia JE. Catabolic effects of continuous human PTH (1-38) in vivo is associated with sustained stimulation of RANKL and inhibition of osteoprotegerin and geneassociated bone formation. Endocrinology $20011424047-4054$. (doi:10.1210/en.142.9.4047)

6 Bellido T, Ali AA, Gubrij I, Plotkin LI, Fu Q, O’Brien CA, Manolagas SC \& Jilka RL. Chronic elevation of parathyroid hormone in mice reduces expression of sclerostin by osteocytes: a novel mechanism for hormonal control of osteoblastogenesis. Endocrinology 2005146 4577-4583. (doi:10.1210/en.20050239)

7 Keller H \& Kneissel M. SOST is a target gene for PTH in bone. Bone 200537 148-158. (doi:10.1016/j.bone.2005.03.018)

8 O'Brien CA, Plotkin LI, Galli C, Goellner JJ, Gortazar AR, Allen MR, Robling AG, Bouxsein M, Schipani E, Turner CH, Jilka RL, Weinstein RS, Manolagas SC \& Bellido T. Control of bone mass and remodeling by PTH receptor signaling in osteocytes. PLoS ONE 20083 e2942. (doi:10.1371/journal.pone.0002942)

9 Silvestrini G, Ballanti P, Leopizzi M, Sebastiani M, Berni S, Di Vito M \& Bonucci E. Effects of intermittent parathyroid hormone (PTH) administration on SOST mRNA and protein in rat bone. Journal of Molecular Histology 200738 261-269. (doi:10.1007/s10735007-9096-3)

10 van Bezooijen RL, Roelen BA, Visser A, van der Wee-Pals L, de Wilt E, Karperien M, Hamersma H, Papapoulos SE, ten Dijke P \& Löwik CW. Sclerostin is an osteocyte-expressed negative regulator of bone formation, but not a classical BMP antagonist. Journal of Experimental Medicine 2004199 805-814. (doi:10.1084/jem. 20031454)

11 Li X, Zhang Y, Kang H, Liu W, Liu P, Zhang J, Harris SE \& Wu D. Sclerostin binds to LRP5/6 and antagonizes canonical Wnt signaling. Journal of Biological Chemistry $200528019883-19887$. (doi:10.1074/jbc.M413274200)

12 Ellies DL, Viviano B, McCarthy J, Rey JP, Itasaki N, Saunders S \& Krumlauf R. Bone density ligand, Sclerostin, directly interacts with LRP5 but not LRP5G171V to modulate Wnt activity. Journal of Bone and Mineral Research 200621 1738-1749. (doi:10.1359/jbmr.060810)

13 Balemans W, Ebeling M, Patel N, Van Hul E, Olson P, Dioszegi M, Lacza C, Wuyts W, Van Den Ende J, Willems P, Paes-Alves AF, Hill S, Bueno M, Ramos FJ, Tacconi P, Dikkers FG, Stratakis C, Lindpaintner K, Vickery B, Foernzler D \& Van Hul W. Increased bone density in sclerosteosis is due to the deficiency of a novel secreted protein (SOST). Human Molecular Genetics 200110 537-543. (doi:10.1093/hmg/10.5.537)

14 Li X, Ominsky MS, Niu QT, Sun N, Daugherty B, D 'Agostin D, Kurahara C, Gao Y, Cao J, Gong J, Asuncion F, Barrero M, Warmington K, Dwyer D, Stolina M, Morony S, Sarosi I, Kostenuik PJ, Lacey DL, Simonet WS, Ke HZ \& Paszty C. Targeted deletion of the sclerostin gene in mice results in increased bone formation and bone strength. Journal of Bone and Mineral Research 200823 860-869. (doi:10.1359/jbmr.080216)

15 Ominsky MS, Vlasseros F, Jolette J, Smith SY, Stouch B, Doellgast G, Gong J, Gao Y, Cao J, Graham K, Tipton B, Cai J, Deshpande R, Zhou L, Hale MD, Lightwood DJ, Henry AJ, Popplewell AG, Moore AR, Robinson MK, Lacey DL, Simonet WS \& Paszty C. Two doses of sclerostin antibody in cynomolgus monkeys increases bone formation, bone mineral density, and bone strength. Journal of Bone and Mineral Research 2010 25 948-959. (doi:10. 1002/jbmr.14)

16 Padhi D, Stouch B, Jang G, Fang L, Darling M, Glise H, Robinson M, Harris S \& Posvar E. Anti-sclerostin antibody increases markers of bone formation in healthy postmenopausal women. Journal of Bone and Mineral Research $2007 \mathbf{2 2}$ S37.

17 Winkler DG, Sutherland MK, Geoghegan JC, Yu C, Hayes T, Skonier JE, Shpektor D, Jonas M, Kovacevich BR, Karen StaehlingHampton KS, Appleby M, Brunkow ME \& Latham JA. Osteocyte control of bone formation via sclerostin, a novel BMP antagonist. EMBO Journal 200322 6267-6276. (doi:10.1093/emboj/ $\operatorname{cdg} 599)$

18 Robling AG, Niziolek PJ, Baldridge LA, Condon KW, Allen MR, Alam I, Mantila SM, Gluhak-Heinrich J, Bellido TM, Harris SE \& Turner $\mathrm{CH}$. Mechanical stimulation of bone in vivo reduces osteocyte expression of Sost/sclerostin. Journal of Biological Chemistry 2008 283 5866-5875. (doi:10.1074/jbc.M705092200)

19 Kramer I, Loots GG, Studer A, Keller H \& Kneissel M. Parathyroid hormone (PTH) induced bone gain is blunted in SOST overexpressing and deficient mice. Journal of Bone and Mineral Research 201025 178-189. (doi:10.1359/jbmr.090730)

20 Mirza FS, Padhi ID, Raisz LG \& Lorenzo JA. Serum sclerostin levels negatively correlate with parathyroid hormone levels and free estrogen index in postmenopausal women. Journal of Clinical Endocrinology and Metabolism 201095 1991-1997. (doi:10. 1210/jc.2009-2283)

21 Drake MT, Srinivasan B, Modder UI, Peterson JM, McCready LK, Riggs BL, Dwyer D, Stolina M, Kostenuik P \& Khosla S. Effects of parathyroid hormone treatment on circulating sclerostin levels in postmenopausal women. Journal of Clinical Endocrinology and Metabolism, 2010. (doi:10.1210/jc.2010-0720)

22 Mödder UI, Hoey KA, Amin S, McCready LK, Achenbach SJ, Lawrence RB, Joseph ML \& Khosla S. Relation of age, gender, and bone mass to circulating sclerostin levels in women and men. Journal of Bone and Mineral Research, 2010. (doi:10.1002/jbmr.217)

23 Datta NS \& Abou-Samra AB. PTH and PTHrP signaling in osteoblasts. Cellular Signalling 200921 1245-1254. (doi:10. 1016/j.cellsig.2009.02.012)

24 Jilka RL. Molecular and cellular mechanisms of the anabolic effect of intermittent PTH. Bone 200740 1434-1446. (doi:10.1016/ j.bone.2007.03.017)

Received 2 September 2010

Accepted 3 September 2010 